\title{
The COVID-19 Pandemic and Probation in Chile: Remote Supervision and Regional Differences
}

\author{
Sebastián Galleguillos ${ }^{1}$ - Mauricio Sánchez $\mathrm{Cea}^{2} \cdot$ Deborah Koetzle $^{1} \cdot$ Jeff Mellow $^{1} \cdot$ Diego Piñol Arriagada $^{2}$. \\ Craig Schwalbe ${ }^{3}$
}

Received: 15 September 2021 / Accepted: 19 January 2022 / Published online: 3 February 2022

(c) The Author(s), under exclusive licence to Springer Nature Switzerland AG 2022

\begin{abstract}
The COVID-19 pandemic forced Chilean probation officers to adopt remote supervision technologies to maintain contact with their clients. Considering remote contact was scarcely used by Chilean probation officers before the pandemic, this change demands studying the impact of the pandemic remote supervision on the contact between officers and clients. To address this problem, we surveyed probation officers $(n=326)$ exploring the impact of COVID-19 on clients, officers, and the use of remote supervision across six Chilean macro-geographical regions representing the entire country: Extreme North, North, Santiago (Metropolitan Region), Middle South, South, and Extreme South. The survey includes demographics on probation officers at the national level, presenting data about their workload and agency for the first time. The results suggest that probation officers drastically changed how they contact their clients, shifting from primarily in-person communication to remote contact including videoconferencing, calls, and text messages. Our findings indicate that clients were heavily impacted by the pandemic in different psychosocial aspects and had low rates of access to technology. Finally, the macro-geographical analysis reveals how demographics, agency characteristics, technology access, and COVID-19 impact vary throughout the country. We conclude by discussing the relevance of the geographical and socioeconomic context before implementing remote supervision as community supervision core practice.
\end{abstract}

Keywords Probation $\cdot$ Remote supervision $\cdot$ Chile $\cdot$ Community corrections $\cdot$ COVID-19

Sebastián Galleguillos

sgalleguillos@jjay.cuny.edu

Mauricio Sánchez Cea

msanchez@iap.uchile.cl

Deborah Koetzle

dkoetzle@jjay.cuny.edu

Jeff Mellow

jmellow@jjay.cuny.edu

Diego Piñol Arriagada

diego.pinol@iap.uchile.cl

Craig Schwalbe

css2109@columbia.edu

1 John Jay College of Criminal Justice (CUNY), 524 W 59th Street, New York, NY 10019-1093, USA

2 Instituto de Asuntos Públicos, Universidad de Chile, Santiago, Chile

3 School of Social Work, Columbia University, New York, USA

\section{Criminal Justice Responses Toward COVID-19 in Chile}

The COVID-19 pandemic has disrupted the routines of people working in government agencies, non-governmental organizations, and social services around the world. Nowhere is this more evident than in community corrections. Two main elements of a community supervision officer's job are to monitor clients (e.g., compliance with conditions of supervision, surveillance, drug testing) and intervene when needed (e.g., crisis involvement, counseling) to help with their successful reintegration. Pre-COVID-19, the majority of these interactions occurred face to face; however, these interactions have changed considerably since the pandemic began. In-person contacts now require an extra layer of safety protocols (e.g., personal protective equipment, social distancing, and sanitizing surfaces) and, at times, have been replaced with remote interactions, particularly when lockdown policies have been implemented to control the spread of the virus. 
As in many countries, the Chilean government adopted various measures to mitigate the pandemic's impact on their correctional system after experiencing one of the highest infection rates in Latin America at both the community and prison level (see Byrne et al., 2020). The measures included three principal strategies: (1) shift the face-to face interaction of criminal justice actors to remote contact, (2) implement health protocols within correctional facilities, and (3) divert low-risk incarcerated individuals from prisons to reduce institutional infection rates.

The shift to remote contacts can be traced to March 2020, when the Poder Judicial (Judiciary) started passing guidelines (auto acordados and oficios) to allow court hearings online during the adjudication process (Actas 41, 42, 53, and 51, 2020). During this same time period, Gendarmería de Chile, the agency that oversees adult prisons and adults under community supervision in Chile, requested permission to supervise their probation clients remotely to prevent the spread of the virus among officers and clients (Oficio 192/2020). Collectively, these actions set the stage for remote supervision of those on community supervision.

During the same time, recognizing that prisons with high population density are an ideal incubator for the spread of the coronavirus, the Ministry of Health and Gendarmería de Chile began a number of risk mitigation strategies. The measures to reduce the risk of infection within Chilean prisons included implementing health protocols, releasing incarcerated people, suspending in-person visits, and promoting vaccination campaigns against influenza to slow down the spread of the coronavirus in the prisons (Prison Insider, 2021).

Beyond creating allowances that would allow for remote contact, Chilean authorities also used a wide variety of mechanisms (e.g., probation, parole, house arrest, suspended sentences, and a Presidential Pardon) to divert individuals from entering prison while simultaneously securing early release for some incarcerated persons, including people with underlying health conditions or convicted of nonviolent crimes (Marmolejo et al., 2020). Between March 2020 and October 2020, a total of 5660 releases have been granted, which accounts for approximately $14 \%$ of the total prison population in Chile (Marmolejo et al., 2020).

Research examining the impact of COVID-19 on the criminal justice system in Chile and Latin America has been relatively limited. Much of the research has used case studies comparing the pandemic's impact on local criminal justice systems, including descriptions of the prison measures adopted by each country in response to the pandemic (see CEJA, 2020; Marmolejo et al., 2020; Prison Insider, 2021; Rapisarda et al., 2020). Although Chile has been included in this body of research, there has only been one study, to our knowledge, which has specifically examined the impact of COVID-19 on criminal justice related issues in Chile.
Bhalotra et al. (2021) explored the impact of COVID-related lockdowns on domestic violence across 116 Chilean municipalities. Similar to the results from a systematic review by Kourti et al. (2021), they found an increase in the use of shelters and helpline calls but a decrease in domestic violence reports to the police.

To our knowledge, this study will be the first to systematically explore the impact of COVID-19 on the community correction population and staff in Latin America, using a sample from Chile for the analysis. This exploratory research is critical for the probation field and Chilean criminal justice policies for the following reasons. First, in Chile, there is a lack of data at the national level on the demographics and characteristics of probation officers, even before the pandemic started. This study will help address this gap by providing basic information about probation officers' demographics including age, ethnicity, education, years of experience, and caseloads characteristics. Also, we will provide data about the characteristics of probation facilities across the country such number of staff members and geographical land use to provide an overview of the conditions where probation services are delivered in Chile.

Second, the pandemic provides a unique opportunity to consider how to redesign correctional systems (Nowotny \& Piquero, 2020). Research in the U.S. suggests that community correction agencies responded to the COVID-19 emergency by reducing their face-to-face contact, while, at the same time, implementing communication technologies with their clients "regardless of the risk level" (Viglione et al., 2020, p. 1291). Likewise, studies from Austria (Stempkowski \& Grafl, 2021) and the Netherlands (Sturm et al., 2021) found an increase in the use of remote supervision technologies within European community correction settings. Furthermore, it has been suggested that remote supervision could go beyond the pandemic, leading to possible long-term transformations of this form of community supervision (Schwalbe \& Koetzle, 2021).

Finally, the current study adds to the research on the use of technology for remote supervision. Further empirical examination of clients' and officers' use of technology is essential for understanding the implementation of new supervision policies based on remote contact.

\section{Community Supervision in Chile: The Relevance of Probation}

In Chile, libertad vigilada (probation) is regulated as a pena sustitutiva (non-custodial sanction) by Law 18.216, along with other alternatives to prison. The Chilean legislation has established two modalities of probation, including libertad vigilada, or probation, and libertad vigilada intensiva, or enhanced probation. The supervision length of probation is 
a maximum of three years, while enhanced probation is up to five years, allowing the judges to impose more restrictive measures for those under intensive supervision (e.g., electronic monitoring).

Along with probation, Decreto Ley 321 regulates libertad condicional (parole) for individuals convicted to prison sentences. Parole is granted by the Corte de Apelaciones (Appeals Court). The requirements for parole requests vary depending on the severity of the offense and generally include completing half to two thirds of the prison sentence, exhibiting good behavior, and having a positive psychosocial report regarding reentry and recidivism risk factors (Biblioteca del Congreso Nacional, $\mathrm{s} / \mathrm{n}$ ). As with people on probation, individuals released on parole are supervised by officers from Gendarmería de Chile.

Gendarmería de Chile operates under the supervision of the Ministry of Justice and Human Rights and oversees adults under correctional supervision aiming to assist, supervise, and rehabilitate them (Decreto Ley 2859). In Chile, probation officers must fulfill three minimum requirements, (1) have a college degree in psychology or social work, (2) demonstrate at least one year of work experience in the psychosocial field, and (3) obtain a license provided by the Ministry of Justice and Human Rights to work as a community correction officer (Decreto 629). According to the law, under no circumstance will individuals be able to work as probation officers if they do not have the license required and granted by the Ministry of Justice and Human Rights.

Beyond probation and parole, Gendarmería de Chile is responsible for a wide range of facilities, including facilities for individuals under pretrial detention, female prisons, and male prisons, among others (see Gendarmería de Chile, $\mathrm{s} / \mathrm{n}$ ). The Centros de Cumplimiento Penitenciario are facilities for individuals sentenced to prison and the Centros de Detención Preventiva are meant for individuals under pretrial detention (jails). In this study, we will focus on the Centros de Reinserción Social (rehabilitation facilities), where the activities to coordinate and supervise individuals under noncustodial sentences are developed. In October 2020, there were 42 rehabilitation facilities across the country, comprising a total of 462 probation officers.

As of December 2021, there were 1013 persons under probation supervision and 16,238 under enhanced probation supervision in Chile, comprising about $32 \%$ of the population serving non-custodial sanctions and $17.39 \%$ of the individuals under correctional supervision (Gendarmería de Chile, 2021). As Wilenmann (2020) points out, the rate of people under correctional supervision in Chile has increased over the last two decades. However, the trends for probation and incarceration have moved in the opposite direction: although incarceration rates have been decreasing, probation rates have increased since 2013 (Wilenmann, 2020). These trends indicate the prominent role that probation is taking within the Chilean criminal justice system, illustrating the need to conduct more research to understand the impact of probation in the criminal justice system and the challenges associated with this form of correctional supervision.

Despite the growing use of community supervision sanctions, relatively little is known about its use from either the probation officers' or clients' perspective. The majority of the pieces are theoretical, analyzing the history (see Salinero Echeverría \& Morales Peillard, 2019) and the foundations of non-custodial sentences (see Morales Peillard \& Salinero Echeverría, 2020). Although empirical data are scarce, there is evidence that those on community supervision represent vulnerable groups, much like those in other countries. For example, Salinero Echeverría and Fábrega Lacoa (2020) found that individuals on enhanced probation or in alternatives to incarceration programs have lower levels of education relative to individuals serving other types of non-custodial sentences. Exploring the social context and resources available to clients under probation during COVID-19 is particularly important given the pre-existing disproportionality in crime and resources across Chile.

In Chile, a wide variety of criminal justice studies and governmental reports highlight how victimization and crime rates vary across the country. For example, the household victimization rate for robbery and attempted robbery in the capital Santiago (30.6\%) is higher than the average of the rest of the regions (22.3\%) (Fundación Paz Ciudadana, 2020). In addition, reports by the Chilean police reveal important variations in crime rates across regions including a wide variety of crimes such as crimes against property, sexual crimes, and economic crimes, among others (see Instituto Nacional de Estadísticas, 2019). Given the differences in crime rates, and, by extension, differences in probation populations, we argue that it is important to consider the geographical factor when analyzing probation and remote supervision. This is important since probation services are a response to crime that requires economic and human resources. In the next section, we will describe the main characteristics of the Chilean geography focusing on its inequality and economic aspects that are relevant to understand the broader socioeconomic context of where probation services are delivered.

\section{Chile: Geographical and Economic Inequality}

Chile is one of the longest and narrowest countries in the world, comprising about $4300 \mathrm{~km}$ from north to south, and including a wide diversity of geographical zones throughout the country (Gobierno de Chile, s/n). This particular geography presents challenges for the distribution of social services, including how community supervision is delivered throughout the country. 
In addition to geography, the study of the political and administrative division of Chile is crucial to understanding the nuances and complexities of this country. Chile is divided into 16 regions, where the capital-Región Metropolitana de Santiago - makes up around $40 \%$ of the total population (Instituto Nacional de Estadísticas, 2018) exhibiting the greatest population density in the country. Every region is further subdivided into provincias (56 total) and comunas (345), which would correspond to provinces and municipalities in other countries.

Each Chilean region has its own contextual characteristics which reveal important differences in geographical land use. For instance, in the Region Metropolitana, $96.3 \%$ of the population resides in urban areas, while in Antofagasta that percentage reaches $94.1 \%$ and $93.8 \%$ in Tarapacá. In contrast, in Nuble, $30.6 \%$ of its population resides in rural areas and $69.4 \%$ inhabits urban zones (INE, 2018). Overall, the rural population has tended to decrease over the last decades, dropping from $16.5 \%$ in 1992 to $12.2 \%$ in 2017 , while the urban population increased from 83.5 to $87.8 \%$ in the same time period (INE, 2018).

In addition to geographical differences, Chile is one the most unequal countries around the world given its high Gini Index (Organization for the Economic Co-operation and Development, 2021). Data from the OECD reveal an income inequality gap of "more than $65 \%$ wider than the OECD average, with one of the highest ratios between the average income of the wealthiest $10 \%$ of its population and that of the poorest 10\%" (OECD, 2018). This striking wealth and income disparity are also reflected in the individuals involved in the prison system, where incarcerated individuals usually have a lower income compared to the average individual in the community (Fundación Paz Ciudadana, 2016).

Furthermore, geographical differences in Chile play a key role in explaining the distribution of inequalities across the country (Ramirez et al., 2009). For example, in the Region La Araucanía, $17.4 \%$ of the population are considered poor, while in Magallanes, it is only $5.7 \%$ or $9 \%$ in the capital Region Metropolitana (Encuesta de Caracterización Socioeconómica Nacional, 2020). Overall, individuals in rural areas tend to experience higher rates of poverty and extreme poverty compared to the ones living in urban areas (Encuesta de Caracterización Socioeconómica Nacional, 2020).

However, inequalities in Chile are not restricted to economic dimensions such as income, poverty, or employment. Inequalities in Chile impact more disadvantaged regions, women, and indigenous minorities, including a wide variety of issues such as access to education, political power, and dignity (Programa de las Naciones Unidas para el Desarrollo, 2017). More recently, the social inequalities of Chile have been reflected in the effects of the COVID mitigation measures. For example, Gozzi et al. (2021) studied the impact of the full lockdown imposed on May 15, 2020 in the Chilean capital, finding that comunas (municipalities) with higher Human Development Index (HDI) reduced their mobility to a greater degree than other comunas. As a result, these municipalities experienced fewer death and COVID-19 cases than disadvantaged municipalities.

We argue that the impact of COVID-19 on probation practices should be understood within this context of geographical differences and economic inequalities. Since probation is a form of community supervision that requires human and economic resources, integrating Chilean contextual differences reveals important insights on the impact of COVID-19 and the implications of remote practices for probation agencies and clients. Thus, this study will explore the impact of COVID-19 on the interaction between probation officers and clients, placing special attention on psychosocial consequences for probation officers and clients and the social conditions under which remote supervision has been implemented.

\section{Research Questions}

This study will address the following research questions: (1) How did COVID-19 impact the officers' and clients' lives in Chile? (2) How did COVID-19 change the contact strategies used by probation officers in Chile? (3) What are the differences between macro-geographical regions?

\section{Methods}

\section{Data Collection}

This study is a replication of a national survey of probation and parole officers previously implemented in the United States (Koetzle \& Schwalbe, 2020; Schwalbe \& Koetzle, 2021) and adapted to the Chilean context by the second and fifth authors of this article. To collect the data, we partnered with Gendarmería de Chile and sent the survey invitations and informed consent documents, via email, to probation officers in October 2020. Gendarmería de Chile followed up with officer responses sending reminders over October 2020 via email. The participation was voluntary, anonymous, and did not include any economic incentive.

\section{Sample}

At the time of the survey, there were 462 probation officers across 42 rehabilitation facilities across Chile. The sample comprises 326 probation officers, representing a $70.6 \%$ response rate. The criterion to select participants was being a probation officer supervising a case for at least three months 
Table 1 Macro-geographical regions

\begin{tabular}{|c|c|c|c|c|c|}
\hline Macro-geographical region & Region & $\mathrm{N}^{\circ} \mathrm{CRS}$ & $\begin{array}{l}\text { Probation officers } \\
(N)\end{array}$ & Sample $(n)$ & Participation \% \\
\hline \multirow[t]{4}{*}{ Extreme North } & XV_-Arica y Parinacota & 1 & 12 & 6 & 50.0 \\
\hline & I-Tarapacá & 2 & 12 & 7 & 58.3 \\
\hline & II-Antofagasta & 2 & 22 & 14 & 63.6 \\
\hline & Sub-total & 5 & 46 & 27 & 58.7 \\
\hline \multirow[t]{4}{*}{ North } & III-Atacama & 2 & 12 & 10 & 83.3 \\
\hline & IV_Coquimbo & 3 & 19 & 16 & 84.2 \\
\hline & V - Valparaíso & 6 & 54 & 37 & 68.5 \\
\hline & Sub-total & 11 & 85 & 63 & 74.1 \\
\hline \multirow[t]{2}{*}{ Metropolitan Region } & Capital-Santiago & 6 & 165 & 113 & 68.5 \\
\hline & Sub-total & 6 & 165 & 113 & 68.5 \\
\hline \multirow[t]{4}{*}{ Middle South } & $\mathrm{VI}-\mathrm{O}$ 'Higgins & 2 & 28 & 20 & 71.4 \\
\hline & VII - Maule & 4 & 28 & 24 & 85.7 \\
\hline & XVI-Ñuble & 1 & 13 & 11 & 84.6 \\
\hline & Sub-total & 7 & 69 & 55 & 79.7 \\
\hline \multirow[t]{5}{*}{ South } & VIII-Bío Bío & 4 & 37 & 24 & 64.9 \\
\hline & IX-La Araucanía & 3 & 24 & 21 & 87.5 \\
\hline & XIV—Los Ríos & 1 & 9 & 5 & 55.6 \\
\hline & $\mathrm{X}$-Los Lagos & 3 & 18 & 11 & 61.1 \\
\hline & Sub-total & 11 & 88 & 61 & 69.3 \\
\hline \multirow[t]{3}{*}{ Extreme South } & XI-Aysén & 1 & 5 & 3 & 60.0 \\
\hline & XII-Magallanes & 1 & 4 & 4 & 100.0 \\
\hline & Sub-total & 2 & 9 & 7 & 77.8 \\
\hline Total & & 42 & 462 & 326 & 70.6 \\
\hline
\end{tabular}

before the pandemic started. Forty-four participants reported that they did not meet this requirement, reducing the final sample to 282 cases. The response rate was above $50 \%$ in all the macro-geographical regions analyzed including Extreme North, North, Santiago (Metropolitan Region), Middle South, South, and Extreme South (see Table 1). The lowest participation was reported in the Extreme North (58\%), and the highest response rate was reported in the Middle South reaching $79 \%$ of the total probation officers working there.

\section{Measures}

\section{Officer Characteristics}

We gathered probation officers' demographics including gender, age, ethnicity, education, years of experience, training, and region. Next, we asked participants to report on their caseload characteristics, rehabilitation facilities characteristics, time spent commuting around their territory, and personal COVID-19 impacts. Based on the original survey (Schwalbe \& Koetzle, 2021), we asked an index of psychosocial impact questions including job loss/suspension, food insecurity, loss of housing/inhabiting a crowded place, school/day care closing, moving in/out, anxiety and mental health, drug/alcohol abuse, and medical problems (Harvey Home Connect, 2020).

\section{Index Client}

After collecting the probation officers' data, we asked them to choose an index case from their caseload using a semirandom technique previously used in the original survey (see Koetzle \& Schwalbe, 2020; Schwalbe \& Koetzle, 2021). This semi-random technique included an alphabetical list of the officers' clients, where they entered their own name in the list, and then chose the next person in the list who has been supervised for a minimum of three months before the pandemic started. Probation officers reported their index clients' demographics, risk level, technological access, and COVID-19 psychosocial impact. Technology access was measured by asking about the clients' access to telephone, smartphone, email, text messaging, videoconferencing, and home computer with internet.

\section{Contact Supervision}

To address the change in the contact before and after the onset of COVID-19, we asked probation officers to report 
contact frequency with their index client pre- and postCOVID disruption. We included five types of contact: inperson, field, telephone, text message, and videoconferencing. We measured this interaction using a five-point scale including less than monthly, once per month, two or three times per month, once per week, and more than once per week (Schwalbe \& Koetzle, 2021).

\section{Macro-geographical Regions}

In addition, we analyzed the demographics, technology access, and contact supervision by macro-geographical regions. We collected data by region and then collapsed the responses into six macro-geographical regions: Extreme North, North, Santiago (Metropolitan Region), Middle South, South, and Extreme South (see Table 1). We collapsed the responses into macro-geographical regions for two reasons. First, considering the small size of some regions and the response rates of our sample, analyzing individual regions could potentially violate the confidentiality of our survey participants. For example, in the Region Magallanes XII, there is only one rehabilitation facility, and we surveyed the four probation officers $(n=4,100 \%)$ who work there. Second, grouping the regional responses into macro-geographical regions helped us to improve the statistical power since the small size of some regions (e.g., Region Magallanes XII) would have precluded the use of some statistical analyses.

\section{Analysis}

We collected the data through the online platform Momentive (former SurveyMonkey) and used the SPSS statistical software package to run the analyses. Along with descriptive statistics, we employed Chi-Square, t-test, and ANOVA analyses to explore how demographics, agency characteristics, technology access, and COVID-19 impact vary across macro-geographical regions. In addition, we employed Marginal Homogeneity Test (MHT) to explore if there were any difference on the frequency contact before and after the onset of COVID-19 among macro-geographical regions.

\section{Results}

\section{Probation Officers and Clients' Demographics}

The results in Table 2 show that probation officers were predominantly female $(72.1 \%)$, in their early 40 s $(M=41.3$, $\mathrm{SD}=6.1)$, and with an average caseload of 38 clients $(M=38, \mathrm{SD}=10.1)$. Although only $14 \%$ of the participants identify themselves as indigenous people, this number increases in extreme regions reaching $33 \%$ of probation officers in the Extreme North and $43 \%$ in the Extreme South. All participants reported having a college degree, an average of 7 years of experience $(M=7.2, \mathrm{SD}=4.41)$, and $89 \%$ hold the license required by the Ministry of Justice and Human Rights to practice as probation officers.

Index clients were predominantly male $(79.1 \%)$ and in their early thirties $(M=32.7, \mathrm{SD}=11.3)$. Like probation officers, $88.7 \%$ of the clients do not belong to any indigenous community. Index clients on average have spent 14 months under supervision when the survey was conducted $(M=14$, $\mathrm{SD}=8.8)$, and almost half of them $(47.2 \%)$ are considered medium recidivism level.

\section{COVID-19 Impact}

As shown in Table 2, there are important differences regarding the COVID-19 psychosocial and economic impact on probation officers' and clients' lives. Overall, index clients' households were reported to have higher rates on almost all of the aspects, including job suspension, food insecurity, falling behind in rent/mortgage, and use of drugs/alcohol. More than half of the clients' households reported job loss/suspension (60.3\%) compared with only a quarter of that percentage among probation officers (15.6\%). Index clients experienced about twice the rate falling behind in rent/mortgage (17\%) and confirmed COVID illness (12.8\%) compared to probation officers. Probation officers did not report any case of food insecurity $(0 \%)$ and drug/alcohol use $(0 \%)$, while around a quarter of index clients were reported with drug/alcohol use (22\%) and $12.4 \%$ experienced food insecurity.

The most common psychosocial and economic impacts among index clients were job/loss suspension (60.3\%) and school/day care closure (45\%), as reported by probation officers (see Table 1). In contrast, fewer probation officers reported job loss or suspension in their own household (15.6\%) but reported higher rates of school/day care closures $(62 \%)$. At the same time, nearly half of probation officers reported anxiety or mental health (43.6\%), but only $28.4 \%$ index clients were perceived to have increased anxiety and mental health issues as a result of COVID-19.

As indicated in Table 2, access to technology among index clients varied depending on the specific type of communication technology. According to probation officers, $70.2 \%$ of the index clients and/or their families have a home phone or cell phone and $63.5 \%$ have access to text messages. However, less than half of index clients have access to communication technologies such as emails (44.3\%), smartphones (43.6\%), and videoconferences (33.7\%). Most importantly, less than a quarter of the index clients were reported as having a computer with access to the internet at home (24.1\%). 
Table 2 Officer and clients' demographics, COVID-19 impact, and technology availability

\begin{tabular}{|c|c|c|}
\hline Variables & Officer & Index client \\
\hline Age, $M(S D)$ & $41.3(6.1)$ & $32.7(11.3)$ \\
\hline \multicolumn{3}{|l|}{ Gender (\%) } \\
\hline Female & 72.1 & 19.9 \\
\hline Male & 27.3 & 79.1 \\
\hline No response & 0.6 & - \\
\hline Other sex & - & 1.1 \\
\hline \multicolumn{3}{|l|}{ Ethnicity (\%) } \\
\hline Non indigenous & 85.8 & 88.7 \\
\hline Indigenous & 14.2 & 5.3 \\
\hline Not sure & - & 6 \\
\hline Mapuche & 69.6 & - \\
\hline Aymara & 10.9 & - \\
\hline Kawesqar & 2.2 & - \\
\hline Rapa Nui & 2.2 & - \\
\hline Others & 15.2 & - \\
\hline \multicolumn{3}{|l|}{ Recidivism risk \% } \\
\hline Low or very low & - & 23 \\
\hline Medium & - & 47.2 \\
\hline High or very high & - & 29.8 \\
\hline \multicolumn{3}{|l|}{ Education (\%) } \\
\hline College degree & 100 & - \\
\hline Master's degree & 22 & - \\
\hline Years of experience & $7.2(4.4)$ & - \\
\hline License & 89.2 & - \\
\hline Caseload & & - \\
\hline Size, M (SD) & $38.0(10.9)$ & \\
\hline Supervision length index case (SD) & $14.0(8.8)$ & - \\
\hline Municipality (\%) & & - \\
\hline Rural & 37 & - \\
\hline Semi-urban & 60.7 & - \\
\hline Urban & 76.4 & - \\
\hline \multicolumn{3}{|l|}{ COVID impacts } \\
\hline Job loss/job suspension (\%) & 15.6 & 60.3 \\
\hline Food insecurity (\%) & 0 & 12.4 \\
\hline Behind in rent/mortgage $(\%)$ & 8.3 & 17 \\
\hline School-day care close $(\%)$ & 62 & 45 \\
\hline Moved in/moved out home (\%) & 13.8 & 13.5 \\
\hline Anxiety or mental health (\%) & 43.6 & 28.4 \\
\hline Medical emergency (\%) & 22.4 & 19.5 \\
\hline Drug/alcohol use (\%) & 0 & 22 \\
\hline Confirmed COVID (\%) & 6.4 & 12.8 \\
\hline \multicolumn{3}{|l|}{ Tech availability } \\
\hline Home computer with internet & - & 24.1 \\
\hline Smartphone & - & 43.6 \\
\hline Text messaging & - & 63.5 \\
\hline Email & - & 44.3 \\
\hline Telephone & - & 70.2 \\
\hline Video conference & - & 33.7 \\
\hline
\end{tabular}

Table 2 (continued)

Index clients were selected using participant caseloads using pseudorandom procedures described in the methods section

\section{Macro-geographical Regions, Demographics, and Agency Characteristics}

The analysis by macro-geographical regions also reveals that geographical location plays a key role shaping the caseloads and agency characteristics reported by probation officers. Table 3 suggests that probation officers' caseload varies across macro-geographical regions $(F=17.768, p<0.01)$, showing different sizes depending on the macro-geographical region analyzed. In this regard, the Metropolitan Region exhibits higher caseloads on average (44.73) while the Middle South (32.35) and South (33.61) report lower caseloads.

Second, the number of staff members per rehabilitation facility also varies across macro-geographical regions $\left(\chi^{2}=273.97, p<0.01\right)$. The Metropolitan Region has the largest number of staff members per rehabilitation facility; all the facilities located in this macro-geographical region have at least 11 staff members, and $87.5 \%$ of them have more than 21 probation officers. In contrast, all the rehabilitation facilities in the Extreme South reported having five or fewer probation officers.

Finally, commuting time also varies depending on the specific macro-geographical region analyzed $\left(\chi^{2}=62.07\right.$, $p<0.01)$. In the southern macro-geographical regions including the Middle South and South, more than 30\% of the probation officers need four or more hours to travel around their assigned CRS territory to manage their client caseload. In contrast, in the North macro-geographical region, 23.1\% of probation officers reported requiring between two and four hours, while $18 \%$ of them reported two hours or less. In the Metropolitan Region, $51 \%$ of the probation officers reported spending two hours or less, and $39.8 \%$ indicated that they need between two and four hours to travel around the CRS territory. These results are consistent with the finding that southern macro-geographical regions have a higher proportion of probation officers reporting covering rural $\left(\chi^{2}=51.303, p<0.01\right)$ and semi-urban municipalities $\left(\chi^{2}=51.669, p<0.01\right)$.

\section{Macro-geographical Regions, COVID-19 Impact, and Technology Access}

As shown in Table 4, job loss/suspension $\left(\chi^{2}=12.35\right.$ $p<0.05)$ and confirmed COVID illness $\left(\chi^{2}=12.30 p<0.05\right)$ have a different impact on index clients depending on the macro-geographical region analyzed. First, we found that $40.6 \%$ of the index clients were reported to have job loss/ suspension in the Metropolitan Region in contrast with the Extreme North (7.1\%) and Extreme South (2.4\%). At the 
Table 3 Macro-geographical regions, demographics, and agency characteristics

\begin{tabular}{|c|c|c|c|c|c|c|c|}
\hline & Extreme North & North & Metropolitan region & Middle South & South & Extreme South & Statistical test \\
\hline \multicolumn{8}{|l|}{ Officer } \\
\hline Age, $M(\mathrm{SD})$ & $40.1(5.6)$ & $41.4(6.2)$ & $42.0(6.1)$ & $40.5(4.7)$ & $40.8(7.1)$ & $43.4(7.5)$ & $F=0.86$ \\
\hline \multicolumn{8}{|l|}{ Gender (\%) } \\
\hline Feminine & 73.1 & 77.4 & 70.8 & 70.9 & 70.5 & 85.7 & \multirow[t]{2}{*}{$\chi^{2}=1.73$} \\
\hline Masculine & 26.9 & 22.6 & 29.2 & 29.1 & 29.5 & 14.3 & \\
\hline Ethnicity: indigenous (\%) & 33.3 & 9.5 & 12.4 & 13.0 & 11.7 & 42.9 & $\chi^{2}=14.65^{*}$ \\
\hline License $(\%)$ & 88.9 & 87.3 & 94.6 & 89.1 & 83.6 & 85.7 & $\chi^{2}=5.77$ \\
\hline Years of experience & $7.3(3.9)$ & $7.8(5.3)$ & $7.0(3.7)$ & $6.6(3.5)$ & $7.8(5.6)$ & $4.9(2.5)$ & $F=1.10$ \\
\hline Caseload, $M(\mathrm{SD})$ & $34.8(8.4)$ & $36.7(10.5)$ & $44.7(9.4)$ & $32.3(10.3)$ & $33.6(10.2)$ & $37.0(3.8)$ & $F=17.77 * *$ \\
\hline \multicolumn{8}{|l|}{ Recidivism risk \% } \\
\hline Low or very low & 14.8 & 19.0 & 10.6 & 10.9 & 26.2 & 28.6 & $\chi^{2}=9.55$ \\
\hline Medium & 77.8 & 74.6 & 71.7 & 60.0 & 62.3 & 57.1 & $\chi^{2}=6.06$ \\
\hline High or very high & 7.4 & 6.3 & 17.7 & 29.1 & 11.5 & 14.3 & $\chi^{2}=14.43^{*}$ \\
\hline \multicolumn{8}{|c|}{ Staff members per facility (\%) } \\
\hline 5 or less & 25.0 & 19.3 & 0.0 & 3.6 & 34.5 & 100.0 & \multirow[t]{4}{*}{$\chi^{2}=273.97 * *$} \\
\hline 6 to 10 & 41.7 & 45.6 & 0.0 & 49.1 & 31.0 & 0.0 & \\
\hline 11 to 20 & 33.3 & 26.3 & 12.5 & 38.2 & 32.8 & 0.0 & \\
\hline 21 or more & 0.0 & 8.8 & 87.5 & 9.1 & 1.7 & 0.0 & \\
\hline \multicolumn{8}{|l|}{ Municipality (\%) } \\
\hline Urban & 87.5 & 66.7 & 81.7 & 78.2 & 70.7 & 71.4 & $\chi^{2}=7.51$ \\
\hline Semi-urban & 45.8 & 71.9 & 35.6 & 78.2 & 81.0 & 85.7 & $\chi^{2}=51.67 * *$ \\
\hline Rural & 25.0 & 43.9 & 12.5 & 60.0 & 55.2 & 57.1 & $\chi^{2}=51.30 * *$ \\
\hline \multicolumn{8}{|l|}{ Commuting time (\%) } \\
\hline $2 \mathrm{~h}$ or less & 45.8 & 31.6 & 49.0 & 14.5 & 17.2 & 28.6 & \multirow[t]{3}{*}{$F=62.07 * *$} \\
\hline 2 to $4 \mathrm{~h}$ & 25.0 & 43.9 & 41.3 & 30.9 & 27.6 & 14.3 & \\
\hline $4 \mathrm{~h}$ or more & 29.2 & 24.6 & 9.6 & 54.5 & 55.2 & 57.1 & \\
\hline \multicolumn{8}{|l|}{ Index client } \\
\hline Age, $M(\mathrm{SD})$ & $34.4(12.9)$ & $30.8(10.0)$ & $33.1(11.7)$ & $32.4(10.2)$ & $33.5(12.2)$ & $26.8(5.4)$ & $F=0.75$ \\
\hline \multicolumn{8}{|l|}{ Gender $(\%)$} \\
\hline Feminine & 16.7 & 28.0 & 14.3 & 19.1 & 23.6 & 40.0 & \multirow[t]{2}{*}{$\chi^{2}=5.88$} \\
\hline Masculine & 83.3 & 72.0 & 85.7 & 80.9 & 76.4 & 60.0 & \\
\hline Ethnicity: indigenous & 0.0 & 7.8 & 4.5 & 4.5 & 7.4 & 33.3 & - \\
\hline Supervision length & $14.3(7.3)$ & $14.8(10.0)$ & $13.1(7.2)$ & $13.3(8.6)$ & $15.2(10.9)$ & $16.8(10.4)$ & $F=0.65$ \\
\hline
\end{tabular}

${ }^{*} p<0.05 * * p<0.01$

same time, confirmed COVID illness was higher in the Metropolitan Region (58.3\%) and lower in the extreme regions such as Extreme North (8.3\%) and Extreme South (2.8\%).

In addition to the COVID-19 impact, we found differences among macro-geographical regions regarding the access to telephone $\left(\chi^{2}=11.55, p<0.05\right)$ and email $\left(\chi^{2}=20.59<0.01\right)$. We found that less than a quarter of the index clients in the North (23.5\%) have email access, while those in the Extreme North (64\%) and Metropolitan Region (56.6\%) were reported the highest levels of access. Regarding telephone communication, the Extreme South reported the lowest access (20\%) but at the same time reported high access to smartphones (80\%). Overall, the North reported low rates including less than a third of index clients having access to home computer with internet (19.6\%), email (23.5\%), and videoconference (27.5\%). Most importantly, all the macro-geographical regions reported less than a half of access to home computer with internet, where Extreme North was the higher (39.6\%) and the lower the South $(16.4 \%)$.

\section{Contact Frequency Pre-COVID and Post-COVID by Macro-geographical Region}

We conducted the macro-regional analysis using Marginal Homogeneity Test (MHT) to explore the differences and tendencies across macro-regions regarding contact frequency before and after the onset of COVID-19. Table 5 reports a 
Table 4 Macro-geographical regions, COVID-impact index clients, and technology availability

Extreme North North $\begin{aligned} & \text { Metropolitan } \\ & \text { region }\end{aligned}$ Middle South $\quad$ South $\quad$ Extreme South $\chi^{2}$
region

\begin{tabular}{|c|c|c|c|c|c|c|c|}
\hline \multicolumn{8}{|l|}{ Tech availability (\%) } \\
\hline Home computer with internet & 36.0 & 19.6 & 26.3 & 27.7 & 16.4 & 20.0 & 4.92 \\
\hline Smartphone & 40.0 & 37.3 & 43.4 & 46.8 & 45.5 & 80.0 & 3.94 \\
\hline Text messaging & 64.0 & 68.6 & 58.6 & 63.8 & 69.1 & 40.0 & 3.55 \\
\hline Email & 64.0 & 23.5 & 56.6 & 36.2 & 40.0 & 40.0 & $20.59 * *$ \\
\hline Telephone & 80.0 & 62.7 & 67.7 & 80.9 & 72.7 & 20.0 & $11.55^{*}$ \\
\hline Video conference & 36.0 & 27.5 & 39.4 & 29.8 & 32.7 & 20.0 & 3.15 \\
\hline \multicolumn{8}{|l|}{ Index clients-COVID impacts- (\%) } \\
\hline Job loss/job suspension & 48.0 & 62.7 & 69.7 & 42.6 & 60.0 & 80.0 & $12.35^{*}$ \\
\hline Food insecurity & 16.0 & 13.7 & 11.1 & 8.5 & 14.5 & 20.0 & 1.68 \\
\hline Behind in rent/mortgage & 32.0 & 13.7 & 20.2 & 8.5 & 16.4 & 0.0 & 8.53 \\
\hline School-day care close & 48.0 & 51.0 & 49.5 & 31.9 & 41.8 & 40.0 & 5.16 \\
\hline Moved in/moved out & 20.0 & 11.8 & 15.2 & 4.3 & 16.4 & 20.0 & 5.28 \\
\hline Anxiety or mental health & 28.0 & 25.5 & 31.3 & 25.5 & 29.1 & 20.0 & 1.01 \\
\hline Medical emergency & 20.0 & 15.7 & 24.2 & 19.1 & 12.7 & 40.0 & 4.84 \\
\hline Drug/alcohol use & 8.0 & 23.5 & 26.3 & 27.7 & 14.5 & 20.0 & 6.65 \\
\hline Confirmed COVID & 13.0 & 9.5 & 25.6 & 10.3 & 6.0 & 20.0 & $12.30 *$ \\
\hline
\end{tabular}

$*<0.05 * *<0.01$

significant decrease of in-person contacts in the Extreme North, North, Metropolitan Region, Middle South, and South. For example, in the Metropolitan Region, no officer reported meeting with their index client less than monthly and $58.3 \%$ reported meeting their clients 2 to 3 times per week prior to the pandemic. However, after the onset of COVID-19, $45.8 \%$ of the probation officers in the Metropolitan Region reported meeting their clients less than monthly. In this same vein, the macro-regional analysis indicates a significant decrease of in-field contact in the Metropolitan Region, Middle South, and South.

In contrast, contact through phone calls experienced a significant increase across all the macro-geographical regions analyzed. For instance, in the Extreme North, before the pandemic $62.5 \%$ of the probation participants reported using phone calls less than monthly with their index clients. However, after the pandemic, half of probation officers from the Extreme North reported using phone calls with their index clients 2 or 3 times per month. In this same vein, in the Extreme South, $60 \%$ of the probation officers reported using phone calls less than monthly with their index clients and none of them once a week or more than once a week. After the onset of COVID-19, $40 \%$ of the probation officers in the Extreme South reported using phone calls once a week and $20 \%$ more than once a week.

Finally, videoconferencing and text messaging experienced a significant increase in their use in the Extreme North, North, Metropolitan Region, Middle South, and South. Table 5 suggests that videoconferencing is a novel practice for Chilean probation officers given the scarce use before the pandemic occurred. Before the COVID-19 onset, videoconferencing was used less than monthly in the Extreme North (91.7\%), North (94\%), Metropolitan Region (91.7\%), Middle South (89.4\%), South (96.3\%), and Extreme South (100\%). While the Extreme South did not experience a significant increase in its use of videoconferencing and text messaging, it is important to note its low use of videoconferencing (100\% reported less than monthly) and text messaging ( $80 \%$ reported less than monthly) before the pandemic started.

\section{Discussion}

The macro-regional analysis employed in this study suggested important differences regarding probation officers' characteristics, agency characteristics, technology access, and COVID-19 psychosocial impacts. The macro-regional analysis showed that southern macro-geographical regions exhibit smaller caseloads compared to the Metropolitan Region and have fewer probation officers per rehabilitation facility. At the same time, southern regions reported longer commuting times compared to the Metropolitan Region and northern regions. These findings contribute to the existing criminal justice literature in Chile indicating that geographical differences in prisons, victimization, and crime rates, also extend to probation clients and probation practices. 


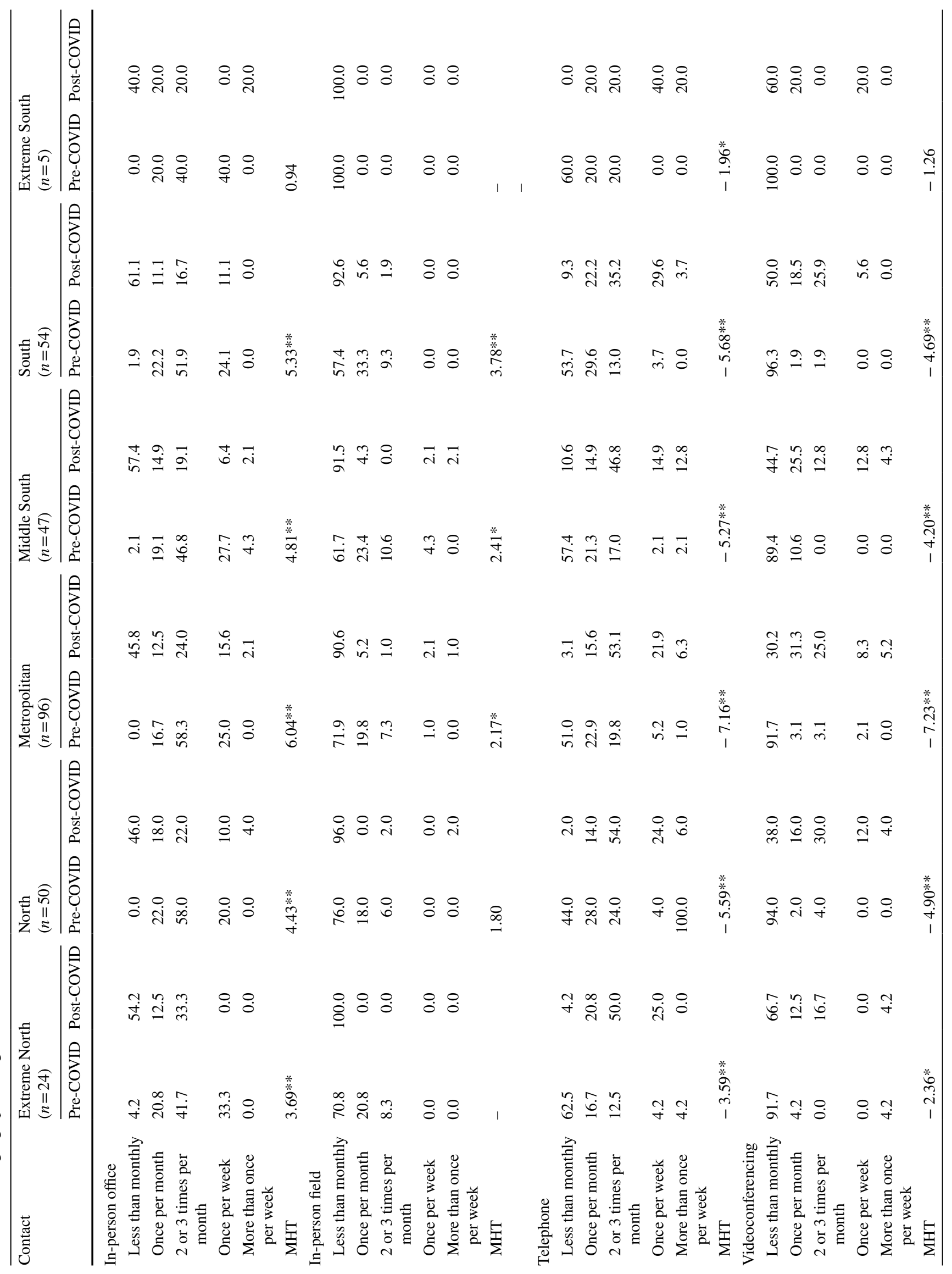




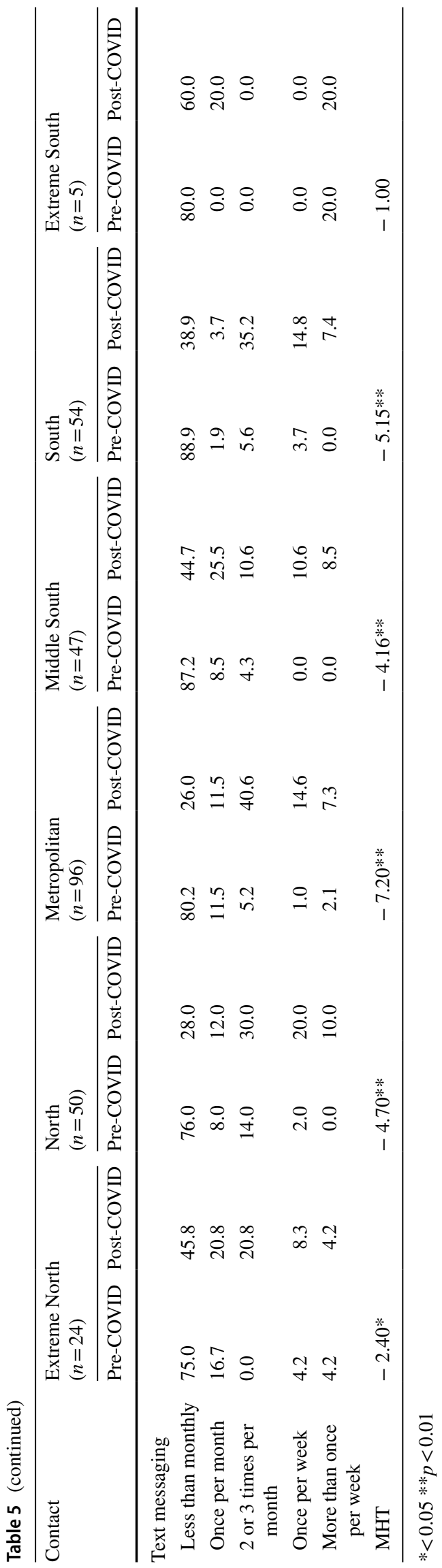

This study suggests that the emergence of COVID-19 has reshaped how probation officers and clients maintain and keep contact, moving from primarily in-person contact to remote supervision. We found that remote supervision is a novel practice for most probation officers in Chile, particularly regarding the case of probation officers located in the Extreme South where none of them reported using videoconferencing before the pandemic occurred. These findings are consistent with the empirical evidence in other socioeconomic and cultural contexts such the US where probation agencies and officers adapted their practices including technology communication to keep in contact with their clients (Schwalbe \& Koetzle, 2021; Viglione et al., 2020) and European-based studies (Stempkowski \& Grafl, 2021; Sturm et al., 2021).

We argue that the full implementation of remote supervision as a core practice should consider both the clients' and probation agencies' perspectives. From the clients' perspective, the implementation of remote supervision practices such as phone calls, videocalls, and text messages requires private access to communication technologies. Our results reveal that although most index clients have access to phones and text messaging, less than half have access to email, smartphones, videoconference, or home computer with internet. The low access to remote communication is not surprising given the levels of socioeconomic inequalities in Chile. These inequalities related to COVID-19 are part of a larger global tendency where the pandemic is "making inequalities more visible" and further increasing them (UNODC, 2020, p. 8). Under this context, we argue remote supervision cannot be used as a primary mechanism for communication if appropriate technological resources are not distributed and ensured to promote fair and equal access to communication technologies.

We argue that the use of remote supervision is not a panacea. The emerging research suggests a number of benefits to the use of remote supervision (see Lockwood et al., 2021; Martin \& Zettler, 2021; Sturm et al., 2021), but it is not without limitations. Beyond disparities in access to technology (Martin \& Zettler, 2021; Phillips et al., 2021), potential disadvantages include the loss of in-person interaction with co-workers and clients (Stempkowski \& Grafl, 2021), struggles in holding clients accountable (Lockwood et al., 2021) and difficulties conducting risk assessments (Phillips et al., 2021). Moreover, although some officers have indicated remote supervision can increase client engagement (Norton, 2020), others have found that remote contacts pose engagement challenges, particularly for newer clients (Phillips et al., 2021).

Furthermore, the focus on disparate access to communication technologies is consistent with the findings on COVID-19 psychosocial and socioeconomic impact on clients and probation officers. The results of our survey suggest 
that index clients were perceived to have been heavily impacted by the pandemic, with higher rates than probation officers in almost all psychosocial aspects including job loss/ suspension, food insecurity, falling behind in rent/mortgage, and use of drug/alcohol. Also, our findings suggest that the impact was uneven across macro-geographical regions, showing that index clients were reported to be heavily impacted in the Extreme South by higher rates of job loss/ suspension (80\%), while the Metropolitan Region reported more than a quarter of COVID illness cases (25.6\%).

Given the inequality and disparity across zones, we argue the implementation of remote supervision should also consider the specific socioeconomic conditions of each macrogeographical region. If the social context of each macrogeographical region is not addressed properly, remote supervision could constitute a practice that further increases inequalities, giving more flexibility to wealthy clients while placing more strain (e.g., time and money in transportation) on disadvantaged individuals without access to remote technologies nor the skills to use them. On the other hand, if clients are provided with the technological resources and skills to perform remote contact such as videoconferencing, remote communication could lessen the burden on clients and promote successful rehabilitation reducing the efforts needed for in-person contact such as finding day care for their children or asking for time off in their jobs to travel to the rehabilitation facility (see Lockwood et al., 2021).

Related, the implementation of remote supervision as a core practice should also consider the land composition, staffing levels, and financial resources. As the results suggest, the Southern macro-geographical regions of Chile report higher rates of rural municipalities, fewer staff members per rehabilitation facility, and longer commuting periods. Using a blended approach to supervision, as advanced by Sturm et al. (2021) would allow for a balance of both in-person and remote contacts. In this approach, the balance of in-person and remote supervision may vary across regions and client access to technology. This approach could lead to a better distribution of agency resources, particularly in regions that require officers to spend long periods of time traveling back and forth for face-to-face meetings and those centers with fewer staff members.

The use of remote supervision should fulfill minimum requirements before its implementation as a core practice. We argue that the use of remote contact should be the result of a mutual agreement between probation officers and clients, becoming an alternative to some in-person contacts only if both clients and officers agree that it is beneficial for the working relationship.

While remote supervision could also constitute a practice that might help to better distribute the already limited resources, it is important to acknowledge there is a cost associated with remote technologies (Viglione et al., 2020).
Martin and Zettler (2021) reported that $75 \%$ of probation administrators stated that financial issues hindered their ability to integrate more technological services into their agencies. Therefore, the use of remote supervision requires considering budget restrictions, especially in regions where probation agencies have already limited budgets.

Overall, the macro-geographical region analysis supports the argument that there is not a single reality in Chile regarding the situation of probation officers and their clients. The psychosocial impact of COVID-19 on index clients is different across macro-geographical regions, revealing different levels of technology access. Considering job loss/suspension was higher in the Extreme North (80\%) compared to other macro-regions, it is important for probation agencies considering this broader socioeconomic context when evaluating the job performance of their clients.

Future studies on remote communication and community supervision should explore how clients and probation officers understand communication within the context of community supervision. Research exploring the benefits, advantages, limitations, and overarching social context of remote supervision can inform how and when remote practices should be implemented to provide a more supportive service. In addition, future research should explore the longterm effects of remote supervision in community corrections settings, including how the use of remote contacts is related to client experiences and supervision outcomes. Finally, future studies should explore how remote technologies can be used to improve criminal justice practices, both within correctional settings and across the broader system.

\section{Limitations}

This study has two important limitations regarding the generalizability of the findings and the measures employed. First, like the original survey implemented in the United States (Schwalbe \& Koetzle, 2021), the measures of the index clients are based on the probation officers' perception of their clients' situation. This technique is vulnerable to memory problems and self-bias. Although we implemented and described a semi-random process to select the client, the index client selected does not necessarily represent the typical client of each probation officer.

Second, this study relied on macro-geographical regions to conduct the geographical analysis on the variables measured. The use of macro-geographical regions allows us to have a broad perspective about the geographical impact on the probation field but does not allow us to see the differences at the regional and intra-regional levels. Therefore, future studies should include variables at different administrative and political levels including comunas (municipalities) and regions. 
Finally, it is important to note that this study was implemented in October 2020 and, therefore, constitutes a snapshot of that specific period in Chile. Given the mutability of the pandemic, other external factors such as the availability of vaccines, the emergence of new COVID-19 variants, lockdowns, and imposition of new restrictions can change the scenario where remote supervision is evaluated and implemented.

\section{Conclusion}

The results of this study suggest that probation officers in Chile drastically changed how they contact their clients, shifting from primarily in-person communication to remote contact including videoconferencing, calls, and text messages. Like probation studies conducted in other countries such as the U.S, remote contact is a novel practice for the majority of probation officers in Chile. Using a sample from Chile for the analysis, we found that community correction staff from Latin America has also adapted their capabilities to continue working with clients regardless of the restrictive measures imposed by the COVID-19 pandemic.

Our findings support the idea that geographical location matters when evaluating and studying the conditions under which probation services are delivered in Chile. This argument is supported by the relevance of macro-geographical regions when analyzing COVID-19 impact, access to technologies, number of staff members per facility, and commuting periods. These findings add to the existing literature in Chile focused on the impact of geographical location on criminal justice issues such as crime rates or victimization. Most importantly, these findings suggest the critical relevance of geography to design and implement remote supervision as a core community supervision practice.

Second, the results on the clients' technology access to communication technologies suggest that less than a half of index clients have access to home computers with internet. These findings are consistent with the larger psychosocial impact of COVID-19 on household clients compared to probation officers, revealing higher rates of job loss/suspension, food insecurity, falling behind in rent/mortgage, and use of drugs/alcohol. Thus, the results suggest that the vulnerabilities of clients were present before the pandemic (low technology access) and were further exacerbated by the pandemic (high psychosocial impact).

We posit that the implementation of remote supervision should consider the different socioeconomic realities across the country. If the socioeconomic inequalities are not addressed properly, remote supervision could constitute a practice that further increases inequalities, giving more flexibility to wealthy clients while placing more strain on disadvantaged individuals without access to remote technologies nor the skills to use them. The balance between in-person meetings and remote supervision could lead to a better distribution of agency resources considering the long periods of time where officers spend traveling back and forth for faceto-face meetings and the reduced size of the staff members in each facility. Finally, we argue that remote contact should be a mutual agreement between probation officers and clients, becoming an alternative to some in-person contacts only if both clients and officers agree that it is beneficial for the working relationship.

Acknowledgements We thanks to two anonymous reviewers and Katy Pugliese for their thoughtful comments.

Funding The author(s) received no financial support for the research, authorship, and/or publication of this article.

\section{Declarations}

Conflict of interest The author(s) declared no potential conflicts of interest with respect to the research, authorship, and/or publication of this article.

\section{References}

Bhalotra, S., Brito, E., Clarke, D., Larroulet, P., \& Pino, F. J. (2021). Dynamic impacts of lockdown on domestic violence: Evidence from multiple policy shifts in Chile (No. wp 2021-189). World Institute for Development Economic Research (UNU-WIDER).

Biblioteca del Congreso Nacional ( $\mathrm{s} / \mathrm{n})$. Guía legal sobre: Libertad condicional. https://www.bcn.cl/leyfacil/recurso/libertad-condi cional [Consulted: 01/03/2021].

Byrne, J., Rapisarda, S. S., Hummer, D., \& Kras, K. R. (2020). An imperfect storm: Identifying the root causes of covid-19 outbreaks in the world's largest corrections systems. Victims \& Offenders, 15(7-8), 862-909.

Centro de Estudios de Justicia de la Américas. (2020). Estado de la justicia en America Latina bajo el COVID 19. Medidas generals y uso de TICs en procesos judiciales. https://biblioteca.cejamericas. org/handle/2015/5648

Encuesta de Caracterización Socioeconómica Nacional (2020). CASEN 2020 en pandemia. http://observatorio.ministeriodesar rollosocial.gob.cl/storage/docs/casen/2020/Resumen_e_resul tados_de_Pobreza_por_Ingresos_y_Distribucion_de_Ingresos. pdf [Consulted: 09/11/2021]

Fundación Paz Ciudadana. (2016). Estudio sobre los niveles de exclusión en personas privadas de libertad. https://pazciudadana. $\mathrm{cl} /$ biblioteca/documentos/estudiosobrelos-niveles-de-exclusionen-personas-privadas-de-libertad/

Fundación Paz Ciudadana. (2020). Índice Paz Ciudadana. https://pazci udadana.cl/proyectos/documentos/indice-paz-ciudadana-2020/ [Consulted: 09/11/2021].

Gendarmería de Chile. (2021). Estadística penitenciaria. https://www. gendarmeria.gob.cl/estadisticaspp.html [Consulted: 01/09/2022].

Gendarmería de Chile. (s/n). Establecimientos penitenciarios. Online access: https://www.gendarmeria.gob.cl/establecimientos.html [Consulted: 09/11/2021].

Gobierno de Chile. (s/n). Nuestro país. Online access: https://www. gob.cl/nuestro-pais/ [Consulted: 09/03/2021]. 
Gozzi, N., Tizzoni, M., Chinazzi, M., Ferres, L., Vespignani, A., \& Perra, N. (2021). Estimating the effect of social inequalities on the mitigation of COVID-19 across communities in Santiago de Chile. Nature Communications, 12(1), 1-9.

Harvey Home Connect. (2020). Gulf Coast COVID Survey. https:// www.gulfcoastcovidsurvey.org/ [Consulted: 09/03/2021].

Instituto Nacional de Estadísticas. (2018). Síntesis de resultados Censo 2017. https://www.censo2017.cl/descargas/home/sintesis-de-resul tados-censo2017.pdf

Instituto Nacional de Estadísticas. (2019). Informe anual de Estadísticas Policiales, 2019. https://www.ine.cl/docs/default-source/ estadisticaspoliciales/publicaciones-y-anuarios/estadisticaspoliciales/2019-informeanual estad\%C3\%ADsticaspoliciales. pdf?sfvrsn=b82b340a_2 [Consulted: 09/11/2021].

Koetzle, D., \& Schwalbe, C. S. J. (2020). COVID-19 and community supervision: Stability and change in supervision practices. Perspectives, 44(4), 59-66.

Kourti, A., Stavridou, A., Panagouli, E., Psaltopoulou, T., Spiliopoulou, C., Tsolia, M., Sergentanis, T. N., \& Tsitsika, A. (2021). Domestic violence during the COVID-19 pandemic: A systematic review. Trauma, Violence, \& Abuse. https://doi.org/10.1177/ 15248380211038690

Lockwood, A., Viglione, J., \& Peck, J. H. (2021). COVID-19 and juvenile probation: A qualitative examination of emergent challenges and useful strategies. Criminal Justice and Behavior, 10, 1-20. https://doi.org/10.1177/00938548211046977

Marmolejo, L., Barberi, D., Bergman, M., Espinoza, O., \& Fondevila, G. (2020). Responding to COVID-19 in Latin American prisons: The cases of Argentina, Chile, Colombia, and Mexico. Victims \& Offenders, 15(7-8), 1062-1085.

Martin, K. D., \& Zettler, H. R. (2021). COVID-19's impact on probation professionals' views about their roles and the future of probation. Criminal Justice Review. https://doi.org/10.1177/07340 168211052876

Morales Peillard, A. M., \& Salinero Echeverría, S. (2020). Fundamento político-criminal y naturaleza jurídica de las penas alternativas en Chile. Revista Chilena De Derecho, 47(2), 513-541.

Norton, S. (2020). COVID-19 pandemic: Practitioner reflections on probation practice. Irish Probation Journal, 17, 183-190.

Nowotny, K. M., \& Piquero, A. R. (2020). The global impact of the pandemic on institutional and community corrections: Assessing short-term crisis management and long-term change strategies. Victims \& Offenders, 15(7-8), 839-847.

OECD. (2018). Chile should use upturn to address low productivity and high inequality. https://www.oecd.org/economy/chile-shoulduse-upturn-to-addresslow-productivity-and-high-inequality.htm [Consulted: 07/03/2021].

OECD. (2021). Income inequality (indicator). https://doi.org/10.1787/ 459aa7f1-en. [Consulted: 07/01 2021].
Phillips, J., Westaby, C., Ainslie, S., \& Fowler, A. (2021). 'I don't like this job in my front room': Practising probation in the COVID-19 pandemic. Probation Journal, 68(4), 426-443.

Prison Insider. (2021). Managing uncertainty in prison. Diverse responses to COVID-19. Centro de Estudios Justicia \& Sociedad. https://justiciaysociedad.uc.cl/wpcontent/uploads/2021/04/INFOR ME-COMPARADO-COVID_14-04.pdf

Programa de las Naciones Unidas para el Desarrollo. (2017). Desiguales. Origines, cambios y desafios de la brecha social en Chile. https://www.cl.undp.org/content/chile/es/home/library/ poverty/desiguales--origenescambios-y-desafios-de-la-brechasocial-en-.html

Ramírez, E., Tartakowsky, A., \& Modrego, F. (2009). Importancia de la desigualdad geográfica en Chile. Documento de trabajo/Programa Dinámicas Territoriales Rurales. RIMISP Centro Latinoamericano para el Desarrollo Rural; no. 30.

Rapisarda, S. S., Byrne, J. M., \& Marmolejo, L. (2020). An Examination of COVID-19 outbreaks in South American prisons and jails. Victims \& Offenders, 15(7-8), 1009-1018.

Salinero Echeverría, S., \& Fábrega Lacoa, J. (2020). ¿Contribuye el aumento del catálogo de penas alternativas y el resto de modificaciones legales a cambiar el perfil de la población condenada en el sistema abierto? Evidencia para Chile. Revista Criminalidad, 62(2), 181-198.

Salinero Echeverría, S., \& Morales Peillard, A. M. (2019). Las penas alternativas a la cárcel en Chile. Un análisis desde su evolución histórica. Revista De Derecho (valparaíso), 52, 255-292.

Schwalbe, C. S., \& Koetzle, D. (2021). What the COVID-19 pandemic teaches about the essential practices of community corrections and supervision. Criminal Justice and Behavior., 48, 1300-1316.

Stempkowski, M., \& Grafl, C. (2021). Probationary services in a pandemic. Results from an empirical study in Austria. Probation Journal, 68(4), 444-457.

Sturm, A., Robbers, S., Henskens, R., \& de Vogel, V. (2021). 'Yes, I can hear you now...' Online working with probationers in the Netherlands: New opportunities for the working alliance. Probation Journal, 68(4), 411-425.

UNODC. (2020). Guidance note. Ensuring access to justice in the context of COVID 19. https://www.unodc.org/documents/Advoc acySection/Ensuring_Access_to_Justice_in_the_Context_of COVID-191.pdf [Consulted: 07/03/2021].

Viglione, J., Alward, L. M., Lockwood, A., \& Bryson, S. (2020). Adaptations to COVID-19 in community corrections agencies across the United States. Victims \& Offenders, 15(7-8), 1277-1297.

Wilenmann, J. (2020). Neoliberal politics and state modernization in Chilean penal evolution. Punishment \& Society, 22(3), 259-280. 